Jagdish (2001) and 'Roqan emotional intelligence test' developed by prof. Roquiya zainuaddin and Anjum Ahmed).The sample of the present study comprised of 120 teachers of Government Schools (60 female and 60 male) and 120 teachers of private schools (60 female and 60 male) selected from four district of Haryana State (INDIA) by using stratified random sampling technique. The study was limited to three independent (age, sex, and type of schools) and two dependent variables (Mental health and emotional intelligence).

Result and discussion The findings of the research reveals that there is significant difference between teachers in their mental health with regards to their age, gender and type of schools. Emotional intelligence is an important factor that is positively co-related to the mental of teachers.

Conclusion We must restructure the school environment, which not only help in development of intellects of individuals but also improve the capability of teachers, especially in case of female teachers.

\section{EPIGENETIC PERSPECTIVE OF BURNOUT}

${ }^{1}$ Jelena Bakusic*, ${ }^{2}$ Wilmar Schaufeli, ${ }^{3}$ Stephan Claes, ${ }^{1,4}$ Lode Godderis. ${ }^{1}$ Environment and Health, KU Leuven, Belgium; ${ }^{2}$ Work, Organisational and Personnel Psychology, KU Leuven, Belgium; ${ }^{3}$ Department of Psychiatry, University Hospital Leuven, Belgium; ${ }^{4}$ IDEWE, External Service for Prevention and Protection at Work, Heverlee, Belgium

\subsection{6/oemed-2018-ICOHabstracts.1621}

Introduction Despite burnout received an increasing attention in occupational health, there are no binding diagnostic criteria to identify burnout 'cases'. The main aggravating factor is the overlap between burnout and depression. The lack of diagnostic consensus resulted in several attempts to identify biomarkers of burnout, but the results were inconsistent. However, epigenetic biomarkers of burnout have not been investigated so far even though DNA methylation is implicated as a mediator between environmental stress and psychopatology. Therefore, our aim is to investigate epigenetic (DNA methylation) correlates of burnout, compare them to those present in depression and explore their biomarker potential.

Methods We conducted a systematic literature review to gain an insight into DNA methylation mechanisms related to chronic stress, burnout and depression. The biomarker potential of genes derived from the literature review will be tested in a cross-sectional and a cohort study.

Results We identified four genes as potential burnout biomarkers: glucocorticoid receptor gene (NR3C1), brain derived neurotrophic factor gene (BDNF), serotonin transporter gene (SLC6A4) and tyrosine hydroxylase $(\mathrm{TH})$ gene. Methylation of NR3C1 displayed differed patterns in chronic stress and depression. SLC6A4 was hypermethylated in chronic stress, depression and burnout. Methylation levels of BDNF displayed different patterns associated with work-related stress compared to those correlated with depressive symptoms in the same human sample. Work-related stress affected methylation of TH gene in a single study.

Conclusion Additional research exploring DNA methylation patterns in burnout and comparing them to those in depression could offer a better understanding of epigenetic dimensions beyond these constructs and their overlap. Moreover, carefully designed longitudinal studies are necessary for revealing the cause-effect relationship of epigenetic changes and their clinical correlates.
1503 REDUCED LIFE SATISFACTION IN NORWEGIAN MEDICAL DOCTORS COMPARED TO OTHERS: A 15-YEAR LONGITUDINAL STUDY ON INCREASED IMPORTANCE OF WORK-RELATED FACTORS

${ }^{1}$ Javed Iqbal Mahmood, ${ }^{1,2}$ Kjersti Støen Grotmol, ${ }^{3,4}$ Martin Tesli, ${ }^{1}$ Torbjørn Moum, ${ }^{3,4}$ Ole Andreassen, ${ }^{1}$ Reidar Tyssen*. ${ }^{1}$ Department of Behavioural Sciences in Medicine, Faculty of Medicine, University of Oslo, Oslo, Norway; ${ }^{2}$ Regional Centre of Excellence in Palliative Care, Department of Oncology, Oslo University Hospital, Norway; ${ }^{3}$ Norment, KG Jebsen Centre, Division of Mental Health and Addiction, Oslo University Hospital, Norway; ${ }^{4}$ Institute of Clinical Medicine, Faculty of Medicine, University of Oslo, Oslo, Norway

\subsection{6/oemed-2018-ICOHabstracts. 1622}

Introduction There have been alarming reports about burnout and dissatisfaction in US doctors, but what about doctors in Scandinavian public health? We lack representative and longitudinal studies on adjusted work-related predictors of wellbeing in medical doctors. This study aims to compare Norwegian doctors' life satisfaction with a socio-economical matched population sample, and to analyse long-term work-related predictors of life satisfaction.

Methods Two nationwide cohorts of doctors $(n=1052)$ were surveyed in their final year of medical school (1993/94 and 1999) (T1), and 4 (T2), 10 (T3), and 15 (T4) years later. The population sample was from the Nord-Trøndelag Health Survey. A one-item life satisfaction measure was used for the comparison. Work-related predictors of life satisfaction (3items) from T2 to T4 were analysed and controlled for confounders by mixed models repeated measures.

Results Ninety per cent (947/1052) responded at least once, whereas $42 \%(450 / 1052)$ responded at all 4 periods. The population sample was $n=595$. Life satisfaction level was lower in doctors at $\mathrm{T} 4$ than in the comparison group (5.3 vs 5.7, $\mathrm{p}<0.001$ ), and more doctors were dissatisfied with their life (5.6 vs $2.2 \%, \mathrm{p}=0.006$ ). Adjusted work-related predictors of higher life satisfaction were: work-home stress $(\beta=-0.20$, $95 \% \mathrm{CI}=-0.25-\quad-0.16, \mathrm{p}<0.001)$, perceived job demands $(\beta=-0.10,95 \% \mathrm{CI}=-0.15--0.05, \mathrm{p}<0.001)$, and colleague support $(\beta=0.05,95 \% \mathrm{CI}: 0.04$ to $0.07, \mathrm{p}<0.001)$. Workrelated predictors were more important in the youngest cohort (1999).

Discussion Dissatisfaction with life was almost three times more common among doctors, and work pressures seem to have increased over the last decade. The identified workrelated factors seem to be especially important for doctors, and may partly explain the difference between doctors and others. We have controlled for relevant individual factors, such as personality, social support and negative life events, and also life style factors (such as problematic drinking and physical training).

\section{PSYCHOLOGICAL DISTRESS, EFFORT-REWARD IMBALANCE AND WORK-FAMILY INTERACTIONS IN ECUADORIAN PETROLEUM WORKERS}

${ }^{1}$ Manuel Parra*, ${ }^{2}$ Nury Karina Cabal, ${ }^{1}$ Katja Radon, ${ }^{3}$ Denisse Carvalho. ${ }^{1}$ Center for International Health, University Hospital Munich (LMU). Munich- Germany; ${ }^{2}$ Inscora Instituto Del Corazón, Quito, Ecuador; ${ }^{3}$ Deparment of Community Heath, Universidad Federal do Paraná, Curitiba, Brasil

\subsection{6/oemed-2018-ICOHabstracts. 1623}

Introduction Work in oil industry often has workers living transiently in camps for 1-2 weeks periods. This is a 